\title{
Interprofessional faculty development: integration of oral health into the geriatric diabetes curriculum, from theory to practice
}

This article was published in the following Dove Press journal:

Journal of Multidisciplinary Healthcare

6 December 2013

Number of times this article has been viewed

\section{Georgia Dounis' \\ Marcia Ditmyer ${ }^{2}$ \\ Susan VanBeuge ${ }^{3}$ \\ Sue Schuerman ${ }^{4}$ \\ Mildred McClain' \\ Kiki Dounis ${ }^{1,5}$ \\ Connie Mobley ${ }^{2}$}

'Department of Clinical Sciences, ${ }^{2}$ Department of Biomedical Sciences, ${ }^{3}$ Department of Physiological Nursing, ${ }^{4}$ Department of Physical Therapy, University of Nevada Las Vegas School of Dental Medicine, Las Vegas, NV, USA; ${ }^{5}$ Department of Family Medicine, University of Nevada School of Medicine, Reno, NV, USA
Correspondence: Georgia Dounis University of Nevada Las Vegas School of Dental Medicine, I00I Shadow Lane, \#235 D MS 7425, Las Vegas,

NV 89106, USA

Tel +I 7027742667

Fax +l 7027742672

Email georgia.dounis@unlv.edu
Background: Health care workforce shortages and an increase demand for health care services by an older demographic challenged by oral-systemic conditions are being recognized across health care systems. Demands are placed on health care professionals to render coordinated delivery of services. Management of oral-systemic conditions requires a trained health care workforce to render interprofessional patient-centered and coordinated delivery of health care services. The purpose of this investigation was to evaluate the effectiveness of an interprofessional health care faculty training program.

Methods: A statewide comprehensive type 2 diabetes training program was developed and offered to multidisciplinary health care faculty using innovative educational methods. Videorecorded clinically simulated patient encounters concentrated on the oral-systemic interactions between type 2 diabetes and comorbidities. Post-encounter instructors facilitated debriefing focused on preconceptions, self-assessment, and peer discussions, to develop a joint interprofessional care plan. Furthermore, the health care faculty explored nonhierarchical opportunities to bridge common health care themes and concepts, as well as opportunities to translate information into classroom instruction and patient care.

Results: Thirty-six health care faculty from six disciplines completed the pre-research and post-research assessment survey to evaluate attitudes, knowledge, and perceptions following the interprofessional health care faculty training program. Post-training interprofessional team building knowledge improved significantly. The health care faculty post-training attitude scores improved significantly, with heightened awareness of the unique oral-systemic care needs of older adults with type 2 diabetes, supporting an interprofessional team approach to care management. In addition, the health care faculty viewed communication across disciplines as being essential and interprofessional training as being vital to the core curriculum of each discipline. Significant improvement occurred in the perception survey items for team accountability and use of uniform terminology to bridge communication gaps.

Conclusion: Attitude, knowledge, and perceptions of health care faculty regarding interprofessional team building and the team approach to management of the oral-systemic manifestations of chronic disease in older adults was improved. Uniform language to promote communication across health professionals, care settings, and caregivers/patients, was noted. Interprofessional team building/care planning should be integrated in core curricula.

Keywords: team building, patient-centered care, oral-systemic, older adults

\section{Introduction}

Delivery of health care services and health care workforce shortages are together contributing to increasing complexity across the health care spectrum. A diverse older demographic, challenged by multiple chronic diseases, indicates a need for 
collaborative health care teams. Furthermore, chronic diseases and oral diseases share common lifestyle risk factors with overlapping pathology that requires comprehensive, coordinated, delivery of health care services. ${ }^{1}$ Primary care training and continuing education programs offer excellent discipline-specific programs, cultivate outstanding clinical skills, and nurture individualistic perspectives. ${ }^{2,3}$ However, little to no collaborative practice opportunity exists to prepare the next generation of diverse clinicians to learn about, with, and from each other and translate experience gained into interprofessional evidencebased care for older adults with chronic conditions. ${ }^{4-6}$ Executive administrators often cite health care faculty workforce shortages, inadequate collaborative practice space, and perceived lack of curriculum/clinic time, as demonstrated by misaligned academic calendars, as barriers to interprofessional implementation, whereas faculty personnel feel that to plan and develop interprofessional course work requires rigorous planning, clear educational goals, and clearly defined measures of outcomes with little direct benefit and lack of administrative support or recognition. Faculty associated these issues with the extra effort necessary to implement interprofessional learning. Furthermore, interprofessional learning experiences, when repeated at various levels, were thought to overcome cultural barriers and to cultivate the next generation of interprofessional health care faculty and practitioners. To sustain collaborative practice health care system requires promotion of interprofessional learning environments that include trained faculty.

A federally funded geriatric faculty training program was developed to encourage and support integrated management of chronic disease in older adults. The objective of the interprofessional faculty training program was to design and promote the interprofessional team approach to management of the oral-systemic health care needs of older adults with chronic diseases, using contemporary educational methods. The curriculum components were developed and delivered by program instructors from the School of Dental Medicine, School of Nursing, and Allied Health at the University of Nevada Las Vegas working with the School of Medicine at the University of Nevada Reno. The purpose of this specific investigation was to conduct pre-assessment and post-assessment on health care faculty interprofessional knowledge, attitudes, and perceptions associated with a training intervention targeting the interprofessional team approaches included in this program.

\section{Materials and methods}

A one-day interprofessional training program was developed and offered to statewide diverse health care faculty. The innovative use of standardized patients as well as high-fidelity manikins at the Las Vegas Clinical Simulation Center was essential to implementation of the program. The Canadian Interprofessional Health Collaborative and the Olenick concept model were used to define and design the interprofessional training program framework and concept. ${ }^{7,8}$ Program instructors developed dual focus (high-fidelity simulation and standardized patient), comprehensive, interprofessional, patient-centered scenarios targeting the oral-systemic manifestations of a chronic disease.

\section{Overview of program development and implementation}

Type 2 diabetes was selected as the chronic condition for the training program because of the multifactorial nature of the disease, requiring the skills and talents of multiple health care providers and because of its prevalence among older adults. Type 2 diabetes challenges over 27\% (11 million) older adults, whereas $50 \%$ have been identified with abnormal hemoglobin A1c levels during routine examinations, with an increased incidence among non-Hispanic blacks. ${ }^{1}$ This disease has been identified as the fastest growing chronic disease and the seventh leading cause of death, and contributes to skyrocketing health care costs in excess of $\$ 174$ billion annually. ${ }^{1}$

Type 2 diabetes is a combination of peripheral insulin resistance and insufficient insulin (derangement of $\beta$-cell function) secretion that affects multiorgan systems, with metabolic and vascular components characterized by hyperglycemia. ${ }^{9}$ Polypharmaceutical intervention and other modalities of care may reduce the devastating complications of the disease, but do not restore normoglycemia or reduce adverse drug effects. ${ }^{10-13}$ Oral disease and type 2 diabetes share common risk factors. Both are chronic inflammatory diseases with bidirectional relationships. There is increasing evidence that patients with type 2 diabetes and poor glycemic control have an increased risk of periodontal disease, whereas periodontal disease contributes to increased insulin resistance, leading to increased risk/progression of type 2 diabetes. ${ }^{13,14}$ Older adults diagnosed with a chronic condition like type 2 diabetes require comprehensive care from multiple health care professionals to manage the condition across different care settings; however, there is a lack of communication, collaboration, and coordination of services. . $^{5,15,16}$ These scientific and clinical tenets guided development of the program content. 
The training objectives were to identify, recognize, and incorporate the oral-systemic manifestations of type 2 diabetes into physical assessment of standardized patients and simulation manikins presenting with the disease. Emphasis on team/patient communication and formulation of an interprofessional treatment plan was the goal for the program participants. ${ }^{17}$ Post-encounter with the simulation environments, small group debriefing discussions offered an opportunity to reflect on the experiences. Both self and peer assessment, as well as development of team building skills, were explored in these discussions.

\section{Sequenced program activities}

A statewide announcement that included a program description and registration form was sent to faculty from multiple health professional academic institutions in Nevada. This was a convenience sample that evolved from word-of-mouth and the act of nominating health professional colleagues. The disciplines targeted to participate include medicine, dentistry, allied health, nursing, pharmacy, psychology, and social services. Health care faculty representing the disciplines of medicine, dentistry, nursing, pharmacy, allied health, social services, and psychology registered for the training program. Prior to attending the program, registered health care faculty received background information on oral-systemic manifestations of type 2 diabetes and on interprofessional team development. ${ }^{7}$ On the day of the program, classroom presentations reviewing type 2 diabetes were discussed by multiple health care providers prior to assigning the health care faculty to interprofessional health care teams. Each team included a representative health care faculty from each targeted discipline and assumed the role of team participant, as well as team observer, in each simulated patient (standardized and/or manikin) encounter.

\section{Role of team participants}

Each health care faculty participant received a patient chart that included the medical/social history, physical attributes, clinical findings, and chief complaint of the patient. Teams were allotted 15 minutes to introduce themselves, identify their discipline, and interview and examine the patient (simulation and standardized) in accordance with the guidelines and standards of their specific discipline. During this encounter, the health care faculty participants identified factors associated with risk to the patient's health status, assessed oral and physical status, gathered data, formulated provider/patient treatment goals, formulated discipline/team intervention options, noted outcomes/benchmarks, identified opportunities for coordination of care, and identified how shared responsibility would occur.

\section{Role of team observers}

While health care faculty participants were engaged in the face-to-face patient encounter, a second team of interprofessional health care faculty observed the encounter via hidden monitors. They observed and noted the interactions of each health care faculty participant with the patient as well as the interactions with other members of the team.

Program instructors facilitated post-encounter debriefing (participants/observers) and stimulated discussion. Program participants identified preconceptions, opportunities to bridge interprofessional teaching concepts and knowledge, and opportunities to coordinate care. Program instructors encouraged each health care faculty to self-assess, participate in peer discussion, reflect, process the encounter, participate in formulation of an interprofessional treatment plan, and develop team building skills. A template for the treatment plan included ranking of patient needs/problems, establishing patient/team goals, developing discipline/team intervention strategies, and formulating a follow-up plan. Members of the team recognized their role as an expert in their discipline as well as their role as a member of the team to coordinate the oral-systemic health care needs of older adults with type 2 diabetes. The total debriefing encounter time was 30 minutes.

\section{Learning venue}

Health care faculty participants were provided the opportunity to participate/observe the encounters in a technologically equipped state of the art simulation and standardized patient environment. Simple systems such as video cameras and microphones were used along with sophisticated high definition real-time video equipment with live stream, multiformat, multistandard editing, and live production to meet the highest broadcast specifications. Video recording the encounters enabled instant replay, discussion, and feedback to the faculty trainees, actors, and program instructors, and provided an opportunity for reflection.

\section{Simulation}

High-fidelity clinical simulation is a technologically contemporary controlled environment using sophisticated high-tech software, animated manikins, digital audiovisual recording media, actual medical equipment, and personnel that improvise and customize scenarios to meet the needs of trainees who access this environment. This accelerated both experiential and 
interactive learning in this program. A seamless recreation of a real clinical presentation provided health care faculty trainees with the experience of real-time clinical encounters.

\section{Standardized patient}

Role-playing (standardized patient) was facilitated by trained patient actors, who rehearsed and followed case scripts addressing oral-systemic manifestations of type 2 diabetes.

\section{Assessment}

All health care faculty completed a demographic profile form. Pre-research and post-research assessment surveys were administered to provide documentation of program effectiveness. Volunteer health care faculty gave permission (informed consent) to report their survey data. All personal identifiers were coded in accordance with requirements and approval (\#1010-3623) of the institution's human subjects review board. Health care faculty who refused permission to report their data were permitted to participate in the program, but their survey responses were not included in the outcomes reported in this paper.

\section{Instrumentation}

The research assessment survey consisted of four closed-ended items (multiple choice responses) used to assess knowledge on interprofessional training. Fourteen additional Likert-scale items were used to assess participant attitude (nine items) and perception (five items) about interprofessional teams. Three experts in interprofessional training reviewed the instrument for face and criterion validity. Cronbach's alpha was used to assess internal reliability $(r=0.75)$. Test-retest was used on a small convenience sample $(r=0.83)$ to assess stabilityreliability. The paper-pencil research assessment survey was distributed at the training site before and immediately following training and returned to program staff in a sealed envelope to assure confidentiality. Each envelope was coded to match pre-assessment and post-assessment responses. A data analysis statistician entered all data into an electronic database and completed the analyses, ensuring that the program instructors were blinded to the source of the results. Repeated-measures analyses were used to assess differences between the pre-test and post-test research assessment survey results. Descriptive statistics (means and frequencies) were calculated for knowledge, attitudes, and perception items. Paired $t$-tests were used to compare trainees' mean scores. All data were analyzed using Statistical Package for the Social Sciences version 19 software (IBM Corporation, Armonk, NY, USA).

\section{Results}

Thirty-six health care faculty representing six diverse health care disciplines completed the pre/post research assessment survey, whereas 38 participated in the training program (Table 1). The majority of the health care faculty participants were female, representing nursing (50\%), physical/ occupational therapy $(21 \%)$, pharmacy $(13 \%)$, dentistry (11\%), and medicine (5\%) (see Table 1$)$.

Health care faculty felt more knowledgeable about interprofessional team building and care planning following the interprofessional training program when pre and post results were compared (Table 2). A significant improvement in posttest items was related to knowledge about the importance of interprofessional team building, and to knowledge about team approaches to management of the oral-systemic health care needs of older adults with type 2 diabetes.

Post-test attitude items showing significant improvement were related to the health care faculty communication across disciplines essential to manage the interprofessional care provided to older adults (Table 3 ). The health care faculty felt confident in their ability to recognize the diverse oralsystemic needs of older adults with chronic conditions, and the need to provide health care services as interprofessional teams. The health care faculty valued their team members' contributions to patient care in the pre and post results, yet felt that asking for assistance from a member of the team who was not trained in their discipline only was a sign that they did not know how to do their job effectively. The majority of the health care faculty agreed that duplication and fragmentation of care as a preventable cost justified interprofessional training as being vital to each discipline's core curriculum.

As shown in Table 4, a statistically significant improvement was noted in responses to the five perception survey items on the pre-test versus post-test results. The health

Table I Demographics of geriatric education center faculty training program

\begin{tabular}{lll}
\hline Variable & Frequency & Percentage \\
\hline Sex & & \\
$\quad$ Male & 5 & 13 \\
$\quad$ Female & 33 & 87 \\
Discipline & & \\
Medicine (MD) & 2 & 5 \\
Nursing (NP, RN) & 19 & 50 \\
Dentistry & 4 & 11 \\
Therapy (occupational, physical) & 8 & 21 \\
Pharmacy & 5 & 13 \\
\hline
\end{tabular}

Note: $n=38$.

Abbreviations: NP, nurse practitioner; MD, Doctor of Medicine; RN, registered nurse. 
Table 2 Results for knowledge items

\begin{tabular}{|c|c|c|c|c|}
\hline \multirow[t]{2}{*}{$\begin{array}{l}\text { Knowledge evaluation } \\
\text { items }\end{array}$} & \multicolumn{4}{|c|}{$\begin{array}{l}\text { Faculty trainees responding } \\
\text { correctly to each item }(n)\end{array}$} \\
\hline & $\mathbf{n}$ & Pre & Post & $\begin{array}{l}\text { Improvement } \\
\text { difference }\end{array}$ \\
\hline $\begin{array}{l}\text { I. Which of the following is } \\
\text { not a reason given for why } \\
\text { interprofessional training is } \\
\text { often difficult to implement. }\end{array}$ & 36 & 11 & 26 & $+15^{*}$ \\
\hline $\begin{array}{l}\text { 2. Which of the following } \\
\text { statements is true regarding } \\
\text { the future of health care? }\end{array}$ & 36 & 31 & 33 & +2 \\
\hline $\begin{array}{l}\text { 3. Which of the following best } \\
\text { describes the difference } \\
\text { between "multidisciplinary" } \\
\text { and "interprofessional" } \\
\text { health care team approaches? }\end{array}$ & 36 & 18 & 30 & $+12 *$ \\
\hline $\begin{array}{l}\text { 4. Which of the following } \\
\text { best characterizes an } \\
\text { interprofessional team } \\
\text { approach? }\end{array}$ & 36 & 23 & 34 & $+1 I^{*}$ \\
\hline
\end{tabular}

Notes: *Denotes significant improvement from pre-test to post-test: $t=4.65, d f=35$, $P<0.01$.

care faculty post-training perceptions about team procedural compliance improved significantly. In addition, perception of the need for clear communication was significantly improved and deemed vital. This was especially noted in the transition of care and use of uniform health care professional terminology that was perceived to be needed to bridge communication gaps across facilities, disciplines, and patient/caregivers.

\section{Discussion}

The results of this study indicate that health care faculty knowledge, attitudes, and perceptions about interprofessional team building and care planning improved following participation in this innovative interprofessional faculty training program.

The participants in this study were primarily female, and mainly represented nursing and allied health care (physical and occupational therapy) professionals. The Centre for Advancement of Interprofessional Education in the UK reported that, in their experience, only $7 \%$ of participants in interprofessional programs were physicians. ${ }^{18,19}$ Disinterest in collaborative practices may be due to current payment systems, federal, state, and licensure regulations, disciplinespecific accreditation standards, and low adoption of information technology. ${ }^{6,20,21}$ In spite of the support noted by the Institute of Medicine directives and World Health Organization recommendations, currently in the US there are only five centers for interprofessional education and only $15 \%$ of health care professional schools offer interprofessional programs. ${ }^{6,22-24}$ Implementation of published core competencies for interprofessional collaborative practice requires trained health care faculty to serve as role models in the classroom and in clinical care environments. ${ }^{25}$

Table 3 Responses to attitudes items

\begin{tabular}{|c|c|c|c|c|}
\hline \multirow[t]{3}{*}{ Attitude to evaluation items } & \multicolumn{2}{|l|}{ Agree } & \multicolumn{2}{|l|}{ Disagree } \\
\hline & Pre & Post & Pre & Post \\
\hline & n (\%) & n (\%) & n (\%) & n (\%) \\
\hline $\begin{array}{l}\text { I. An effective team member should value the work of their } \\
\text { fellow team members. }\end{array}$ & $31(86.1)$ & $36(100)$ & 0 & 0 \\
\hline $\begin{array}{l}\text { 2. It is appropriate for one team member to offer assistance } \\
\text { to another who has an excessive workload. }\end{array}$ & $30(83.3)$ & $34(94.4)$ & $2(5.6)$ & 0 \\
\hline $\begin{array}{l}\text { 3. Asking for assistance from a team member is a sign that an } \\
\text { individual does not know how to do his/her job effectively. }\end{array}$ & $10(27.8)$ & $30(83.3)^{*}$ & $26(72.2)$ & $5(13.9)$ \\
\hline $\begin{array}{l}\text { 4. Providing services in interprofessional groups helps professionals } \\
\text { become more sensitive to the diverse needs of patients than } \\
\text { providing services as a single discipline. }\end{array}$ & II (30.5) & $25(69.4)^{*}$ & $25(69.4)$ & $9(22.2)$ \\
\hline $\begin{array}{l}\text { 5. It is appropriate to continue to assert a patient safety concern } \\
\text { until you are certain that it has been heard. }\end{array}$ & $36(100)$ & $36(100)$ & 0 & 0 \\
\hline $\begin{array}{l}\text { 6. Benefits of a team approach in patient care are worth } \\
\text { the extra time it takes to communicate across disciplines. }\end{array}$ & $14(38.9)$ & $32(88.9)^{*}$ & $17(47.2)$ & $3(8.3)$ \\
\hline $\begin{array}{l}\text { 7. Providing services as an interprofessional group produces } \\
\text { better results for patients than working as single disciplines. }\end{array}$ & $32(88.9)$ & $32(88.9)$ & 0 & 0 \\
\hline $\begin{array}{l}\text { 8. A team approach reduces duplication of efforts } \\
\text { and fragmentation in the delivery of care and services. }\end{array}$ & $24(66.7)$ & $34(94.4)^{*}$ & $6(16.7)$ & $2(5.6)$ \\
\hline $\begin{array}{l}\text { 9. Interprofessional training should be a part of education } \\
\text { for every health care professional. }\end{array}$ & $29(80.6)$ & $35(97.2)^{*}$ & 0 & 0 \\
\hline
\end{tabular}

Notes: *Denotes significant improvement from pre-test to post-test: $t=10.78, d f=35, P<0.01$. Responses for strongly agree and agree are collapsed into "agree"; and responses for strongly disagree and disagree are collapsed into "disagree" for purposes of reporting. Responses for neither agree nor disagree are not included. 
Table 4 Results of perception responses

\begin{tabular}{|c|c|c|c|c|}
\hline \multirow[t]{3}{*}{ Perception evaluation items } & \multicolumn{2}{|l|}{ Agree } & \multicolumn{2}{|l|}{ Disagree } \\
\hline & Pre & Post & Pre & Post \\
\hline & n (\%) & n (\%) & n (\%) & n (\%) \\
\hline $\begin{array}{l}\text { I. When a health care professional has a concern about } \\
\text { patient safety, they challenge others until they are sure } \\
\text { the concern has been documented. }\end{array}$ & $22(6 I .1)$ & $32(88.9)^{*}$ & II (30.6) & $3(8.3)$ \\
\hline $\begin{array}{l}\text { 2. Health care professionals correct each other's mistakes } \\
\text { to ensure that procedures are followed properly. }\end{array}$ & $9(25)$ & $27(75)^{*}$ & $22(61.1)$ & $3(8.3)$ \\
\hline $\begin{array}{l}\text { 3. Health care professionals follow a standard method } \\
\text { of sharing information when transferring a patient } \\
\text { to another health care site. }\end{array}$ & $19(52.8)$ & $33(91.7) *$ & $8(22.2)$ & $\mathrm{I}(2.8)$ \\
\hline $\begin{array}{l}\text { 4. Health care professionals use common terminology } \\
\text { when they communicate with each other. }\end{array}$ & $20(55.6)$ & $32(88.9)^{*}$ & $16(44.4)$ & $2(5.6)$ \\
\hline $\begin{array}{l}\text { 5. In your health care facility, health care professionals } \\
\text { correct each other's mistakes to ensure } \\
\text { that procedures are followed properly. }\end{array}$ & $25(69.4)$ & $24(66.7)$ & $5(13.9)$ & $4(11.1)$ \\
\hline
\end{tabular}

Notes: *Denotes significant improvement pre-test and post-test: $t=9.17, \mathrm{df}=35, P<0.01$. Responses for strongly agree and agree are collapsed into "agree"; and responses for strongly disagree and disagree are collapsed into "disagree" for purposes of reporting. Responses for neither agree nor disagree are not included.

Each health care faculty discipline in this study valued the knowledge, experience, and skills of other health care faculty disciplines as being essential and information sharing as critical to development of an interprofessional care plan. In this program, post-training interprofessional foundational knowledge improved. Additionally, by participating in this training program, health care faculty engaged in dialog to explore nonhierarchical teaching opportunities for interprofessional training. However, other studies have reported crowded curriculum schedules, suitability of curricular content, discipline focused interprofessional instructional experiences, funding, issues in liability, cultural entrenchment within academic settings, and clinical care challenges as barriers to interprofessional training. ${ }^{23,26,27}$ Health care faculty were able to distinguish between multidisciplinary and interprofessional care as defined by the Canadian Interprofessional Health Collaborative Education guidelines. ${ }^{7}$ This program improved health care faculty knowledge related to interprofessional team building, and the results reflect what the literature related to health care management of chronic disease supports in terms of approaches to patient care. ${ }^{28,29}$

The attitudes of health care faculty regarding the value of interprofessional care planning improved following the training program. The health care faculty recognized that older adults challenged by type 2 diabetes and comorbidities have a bidirectional relationship with oral disease. Chronic inflammatory diseases involve complex pathologic pathways that affect multiorgan systems and cross discipline-based boundaries when it comes to care. Oral diseases are chronic transmissible bacterial infections with a long latency period prior to clinical manifestation. Individual immunosenescence and endocrinosenescence will modulate expression of type 2 diabetes and oral disease in older adults. ${ }^{30,31}$ The disciplines of nursing, medicine, and social work have been defined as the core disciplines in geriatric care. ${ }^{32}$ However, the nature, scope, and complexity of the oral-systemic health care needs of older adults require that all disciplines work in concert, including oral health care professionals, to coordinate continuous patient-centered care. ${ }^{33}$

The health care faculty in this study recognized that a team approach to the delivery of health care services mitigates duplication and fragmentation of efforts. Similarly, other studies have reported that health care practitioners need to become interdependent to address the complex health care needs of older adults with chronic conditions, and that this may entail power-sharing among various health care professionals if they are to achieve optimal patient-centered health outcomes. ${ }^{34-36}$

Post-training outcomes in this study suggest that interprofessional training should be integrated within the core of all health professional curricula. Researchers have recommended that interprofessional education should occur early in the professional health care curriculum to prevent emergence of stereotypes. ${ }^{37}$ In this study, the use of high-fidelity simulation and standardized patients created real-world learning experiences while addressing the preconceptions of health care faculty about teamwork. In 2013, the Association of American Medical Colleges and Institute of Medicine have recommended the use of simulation centers as a desired learning venue for integrating interprofessional learning opportunities to overcome respective "ivory tower" philosophies..$^{24,38}$ Other studies have concluded that faculty participation in 
interprofessional training programs champions development of an interprofessional curriculum and services that may result in clinicians who are ready for collaborative practice. ${ }^{39,40}$ However, traditional health care education has promoted socialization of trainees within the boundaries of their profession, resulting in limited knowledge of the expertise of other health professionals, and this is viewed as an invisible obstacle to collaborative practice. ${ }^{41,42}$

Other studies have indicated that comprehensive treatment planning entails shared input, trust, mutual engagement, respect, and shared responsibilities to meet oral-systemic patient/caregiver needs. ${ }^{43,44}$ This study identified that asking for assistance from a member of the health care team was perceived as a sign that the individual did not know how to do their job effectively. Some studies have shown that professionals perceive collaborative practice as being associated with potential job elimination or lack of professional autonomy. ${ }^{45-47}$ This issue should be addressed in future studies.

Faculty trainees in this study identified the use of common language by diverse care providers as vital to the management of oral-systemic health care needs and transition of care in older adults. Other studies have identified the use of discipline-specific terminology as a barrier, causing strain in health professional faculty and inability to understand other professional core concepts and content, leading to frustration and disengagement. ${ }^{25,48}$ However, $70 \%-80 \%$ of medical and prescription errors are a result of poor communication (abbreviations and acronyms) and collaboration. ${ }^{49,50}$ The post-training outcomes of this study indicate that a uniform health care terminology is needed to dissolve communication barriers between diverse health care faculties, health care professionals, caregivers, and patients.

\section{Conclusion}

Demographic shifts are shaping health professional education and care delivery systems. There are implications suggesting that the future must foster an amalgamation of the knowledge, skills, and experiences of health care professionals to innovatively address emerging health challenges in older adults. The preliminary findings of this study addressed the opportunities and challenges of health care faculty to encourage and implement interprofessional training focused on the oral-systemic manifestations of chronic disease. Within the parameters of this study, we conclude that:

- interprofessional collaboration improves knowledge, attitudes, and perceptions about team building following participation in an interprofessional training program
- common core health care language is needed to promote communication between health care professionals across faculties and disciplines, and with caregivers and patients

- health care faculty who participated in this study found the learning experiences in interprofessional team building and care planning to be valuable

- future research, which might include a true experimental design and larger sample sizes, would help improve the validity of these results and inspire all health care professionals to embrace this model of learning and practice.

\section{Acknowledgment}

This publication was made possible by a grant (UB4HP19205) from the US Department of Health and Human Services Health Resources and Services Administration HRSA Bureau of Health Professions Division of Public Health and Interdisciplinary Education.

\section{Disclosure}

The authors report no conflicts of interest in this work with respect to the authorship and/or publication of this paper. The opinions and assertions contained herein are those of the authors and are not to be construed as necessarily representing the views of the respective organizations or the Health Resources and Services Administration.

\section{References}

1. Centers for Disease Control and Prevention. National diabetes fact sheet: national estimates and general information on diabetes and prediabetes in the United States, 2011. Atlanta, GA, USA: Department of Health and Human Services, Centers for Disease Control and Prevention; 2011. Available from: http://www.cdc.gov/diabetes/pubs/pdf/ndfs_2011.pdf. Accessed November 10, 2013.

2. Davis D, O'Brien MA, Freemantle N, Wolf FM, Mazmanian P, TaylorVaisey A. Impact of formal continuing medical education: do conferences, workshops, rounds, and other traditional continuing education activities change physician behavior or health care outcomes? JAMA. 1999;282(9):867-874.

3. Forsetlund L, Bjørndal A, Rashidian A, et al. Continuing education meetings and workshops: effects on professional practice and health care outcomes. Cochrane Database Syst Rev. 2009;2:CD003030.

4. Jordan S. Educational input and patient outcomes: exploring the gap. J Adv Nurs. 2000;31(2):461-471.

5. Tinnetti ME, Fried T. The end of the disease era. Am J Med. 2004; 116(3):179-185.

6. Zorek J, Raehl C. Interprofessional education accreditation standards in the USA: a comparative analysis. J Interprof Care. 2013;27(2): 123-130.

7. Canadian Interprofessional Health Collaborative [homepage on the Internet]. Available from:http://www.cihc.ca/resources. Accessed August 8, 2013.

8. Olenick M, Allen LR, Smego RA Jr. Interprofessional education: a concept analysis. Adv Med Educ Pract. 2010;1:75-84.

9. Unger RH, Orci L. Paracrinology of islets and the paracrinopathy of diabetes. Proc Natl Acad Sci U S A. 2010;107(37):16009-16012. 
10. Giorda CB, Avogaro A, Maggini M, et al. Incidence and risk factors for stroke in type 2 diabetic patients: the DAI study. Stroke. 2007;38(4): $1154-1160$.

11. Lipscombe LL, Jamal SA, Booth GL, Hawker GA. The risk of hip fractures in older individuals with diabetes: a population-based study. Diabetes Care. 2007;30(4):835-841.

12. Hampton T. Diabetes drugs tied to fractures in women. JAMA. 2007;297(15):1645.

13. Abrao L, Chagas JK, Schmid H. Periodontal disease and risk for neuropathic foot ulceration in type 2 diabetes. Diabetes Res Clin Pract. 2010;90(1):34-39.

14. Southerland JH, Taylor GW, Offenbacher S. Diabetes and periodontal infection: making the connection. Clin Diabetes. 2005;23(4): 171-178.

15. Centers for Medicare and Medicaid Services. Roadmap for implementing value driven healthcare in the traditional Medicare feefor-service program. 2009. Available from: https://www.cms.gov/ QualityInitiativesGenInfo/downloads/VBPRoadmap_OEA_1-16_508. pdf. Accessed November 9, 2013.

16. Robinson JC. Theory and practice in the design of physician payment incentives. Milbank Q. 2001;79(2):149-177.

17. World Health Organization. Framework for action on interprofessional education and collaborative practice. Geneva, Switzerland: World Health Organization; 2010. Available from: http://whqlibdoc.who.int/ hq/2010/WHO_HRH_HPN_10.3_eng.pdf. Accessed April 11, 2013.

18. Horder J. A national survey that needs to be repeated: Centre for the Advancement of Interprofessional Education. $J$ Interprof Care. 1992;6(1):65-71.

19. Starfield B, Shi L, Macinko J. Contribution of primary care to health systems and health. Milbank Q. 2005;83(3):457-502.

20. Cohen MH, Hrbek A, Davis RB, et al. Emerging credentialing practices, malpractice liability policies, and guidelines governing complementary and alternative medical practices and dietary supplement recommendations: a descriptive study of 19 integrative health care centers in the United States. Arch Intern Med. 2005;165(3):289-295.

21. Cooke M, Irby DM, Sullivan W, Ludmerer KM. American medical education 100 years after the Flexner report. $N$ Engl J Med. 2006;355(13): 1339-1344.

22. Greiner AC, Knebel E. Health Professions Education: A Bridge to Quality. Committee on the Health Professions Education Summit, Institute of Medicine. Washington, DC: National Academies Press; 2003. Available from: http://www.nap.edu/openbook.php?isbn=0309087236. Accessed November 10, 2013.

23. Frenk J, Chen L, Bhutta ZA, et al. Health professionals for a new century: transforming education to strengthen health systems in an interdependent world. Lancet. 2010;376(9756):1923-1958.

24. Institute of Medicine. Interprofessional education for collaboration: Learning how to improve health from interprofessional models across the continuum of education to practice: Workshop summary. Washington, DC: The National Academies Press; 2013. Available from: http://www.nap.edu/catalog.php?record_id=13486. Accessed November 10, 2013.

25. Interprofessional Education Collaborative Expert Panel. Core competencies for interprofessional collaborative practice: report of an expert panel. Washington, DC: Interprofessional Education Collaborative; 2011. Available from: http://www.aacn.nche.edu/education-resources/ ipecreport.pdf. Accessed November 10, 2013.

26. Curran VR, Sharpe D, Forristall J. Attitudes of health sciences faculty members towards interprofessional teamwork and education. Med Educ. 2007;41(9):892-896.

27. Funnell, MM, Anderson RM. Empowerment and self-management of diabetes. Clin Diabetes. 2004;22(3):123-127.

28. Lemieux-Charles L, McGuire WL. What do we know about health care team effectiveness? A review of the literature. Med Care Res Rev. 2006;63(3):263-300.
29. Mealey BL, Rose LF. Diabetes mellitus and inflammatory periodontal diseases. Curr Opin Endocrinol Diabetes Obes. 2008;15(2): 135-141.

30. Gurav AN. Advanced glycation end products: a link between periodontitis and diabetes mellitus? Curr Diabetes Rev. 2013;9(5):355-361.

31. Pincus HA, Keyser DJ, Schultz DJ. RAND/Hartford initiative to build interdisciplinary geriatric health care research centers. Health Aff (Millwood). 2007;26(1):279-283.

32. Flaherty E, Hyer K, Kane R, Wilson N, Whitelaw N, Fulmer T. Using case studies to evaluate students' ability to develop a geriatric interdisciplinary care plan. Gerontol Geriatr Educ. 2003;24(2):63-74.

33. Parchman ML, Noel PH, Lee S. Primary care attributes, health care system hassles, and chronic illness. Med Care. 2005;43(11):1123-1129.

34. Wenger NS, Solomon DH, Roth CP, et al. The quality of medical care provided to vulnerable community-dwelling older patients. Ann Intern Med. 2003;139(9):740-747.

35. Epstein AM. Revisiting readmissions - changing the incentives for shared accountability. N Engl J Med. 2009;360(14):1457-1459.

36. Hoffman SJ, Harnish D. The merit of mandatory interprofessional education for pre-health professional students. Med Teach. 2007;29(8): e235-e242.

37. Association of American Medical Colleges. A Word from the President: "Interprofessional collaboration: we are willing - can we find the way?" Available from: https://www.aamc.org/newsroom/ reporter/may08/88258/may08_word.html. Accessed November 10, 2013.

38. Chen D, Klein D, Minor L. Interdisciplinary perspectives in early intervention professional development in multiple disabilities through distance education. Infants Young Child. 2009;22(2):146-158.

39. Cooper H, Carlisle C, Gibbs T, Watkins C. Developing an evidence base for interdisciplinary learning: a systematic review. $J A d v$ Nurs. 2001;35(2):228-237.

40. Newton PJ, Halcomb EJ, Davidson PM, Denniss AR. Barriers and facilitators to the implementation of the collaborative method: reflections from a single site. Qual Saf Health Care. 2007;16(6): $409-414$.

41. Stone RI, Bryant NS. Educating direct care workers on transitions of care. Annu Rev Gerontol Geriatr. 2012;31(1):167-188.

42. Wright B, Lockyer J, Fidler H, Hofmeister M. Roles and responsibilities of family physicians on geriatric health care teams: health care team member's perspectives. Can Fam Physician. 2007;53(11): 1954-1955.

43. Baerg K, Lake D, Paslawski T. Survey of interprofessional collaboration learning needs and training interest in health professionals, teachers, and students: an exploratory study. $J$ Res Interprof Pract Educ. 2012;2(2):187-204.

44. Wakefield A, Boggis C, Holland M. Team working but no blurring thank you! The importance of team work as part of a teaching ward experience. Learn Health Soc Care. 2006;5(3):142-154.

45. Khatri N, Brown GD, Hicks LL. From a blame culture to a just culture in health care. Health Care Manage Rev. 2009;34(4):312-322.

46. Lahey W, Currie R. Regulatory and medico-legal barriers to interprofessional practice. J Interprof Care. 2005;19 Suppl 1:197-223.

47. Halpern R, Lee MY, Boulter PR, Phillips RR. A synthesis of nine major reports on physicians' competencies for the emerging practice environment. Acad Med. 2001;76(6):605-615.

48. Xyrichis A, Ream E. Teamwork: a concept analysis. $J$ Adv Nurs. 2008;61(2):232-241.

49. Woolf SH, Kuzel AJ, Dovey SM, Phillips RL Jr. A string of mistakes: the importance of cascade analysis in describing, counting, and preventing medical errors. Ann Fam Med. 2004;2(4):317-326.

50. James JT. A new, evidence-based estimate of patient harms associated with hospital care. J Patient Saf. 2013;9(3):122-128. 


\section{Publish your work in this journal}

The Journal of Multidisciplinary Healthcare is an international, peerreviewed open-access journal that aims to represent and publish research in healthcare areas delivered by practitioners of different disciplines. This includes studies and reviews conducted by multidisciplinary teams as well as research which evaluates the results or conduct of such teams or health- care processes in general. The journal covers a wide range of areas and welcomes submission from practitioners at all levels, from all over the world. The manuscript management system is completely online and includes a very quick and fair peer-review system. Visit http://www.dovepress. com/testimonials.php to read real quotes from published authors.

Submit your manuscript here: http://www.dovepress.com/journal-of-multidisciplinary-healthcare-journal 